\title{
Question structure and intonation in Fipa*
}

\author{
Kristina Riedel \\ $Z A S$
}

Cédric Patin

Université Lille 3

This paper sketches the morphosyntactic and prosodic properties of questions in Fipa, discussing three varieties: Milanzi, Nkansi and Kwa. The general word order and morphological patterns relevant to question structures are outlined and different types of $w h$ question constructions are described and tentatively linked to the prosodic features of Fipa questions.

\section{Introduction}

Fipa is a $w h$ in-situ language. While non-fronting of questioned elements is typical for the Bantu languages, Fipa differs from the patterns described for wh-questions in other Bantu languages in a number of ways: subjects can be questioned in the preverbal position (unlike in the vast majority of Bantu languages cf. Sabel \& Zeller 2006; Riedel 2009); there are no special patterns for subject - or object marking associated with questions (cf. Bresnan \& Mchombo 1987; Riedel 2009); there is no conjoint-disjoint distinction and only optional "movement" to the Immediately-After-the-Verb (IAV) position (on these see Watters 1979; Hyman \& Watters 1984; Ndayiragije 1999; Hyman \& Polinsky 2006; van der Wal 2006; Buell 2009; Cheng \& Downing 2009).

In this paper we show that, based on the basic morphosyntactic properties described here, there are no systematic morphosyntactic differences between questions and non-questions in Fipa. We show that instead of marking the clause type by morphosyntactic means, Fipa uses prosody to mark questions.

* Many thanks to the Fipa speakers who provided the data used here, especially: Billia Crispin and Justin Crispin (Kwa); Norbert Ngua, Festus Ngua, William Chokola and Regina Kiwela (Milanzi); Didas Mpokezi, Anna Nguvumaji and Demetus Kanyuka (Nkansi); and Julius Msengezi (Mambwe). The data was collected by Riedel in Tanzania in 2009 and 2010. 
To illustrate this we show how object marking and word order work Fipa before discussing different types of $w h$-questions and the prosody associated with them.

\subsection{The Fipa language}

Fipa, classified as M13, is a Bantu language spoken in South West Tanzania, in the Rukwa Region. There are five linguistic varieties which are associated with the Fipa ethnic group and which might be considered to be dialects of Fipa, especially by Fipa speakers themselves: Milanzi, Nkansi, Kwa and Lungu and Mambwe. According to some sources, Pimbwe and Nyiha are also sometimes included in this group by Fipa speakers (Woodward et al., 2010) but not generally by linguists. Of these varieties, Milanzi, Nkansi and Kwa are only spoken in Tanzania and form one rather closely related group, whereas Mambwe and Lungu are spoken in Tanzania, where they are sometimes considered dialects of Fipa, and in Zambia, where they are considered to be separate languages, or a single language: Mambwe-Lungu. Speaker number estimates for Fipa as a whole are widely divergent, ranging from 195,000 (Lewis, 2009) (not including 230,000 Mambwe-Lungu speakers in Tanzania) to 712,803 (Mradi wa lugha za Tanzania, 2009). SIL researchers also estimated the number of speakers per dialect: Nkansi: 140 000; Kwa: 45 000, and Milanzi: 10 000. The locations of the different varieties of Fipa are shown in figure 1. Here we will only discuss Milanzi, Nkansi and Kwa (but some Mambwe data is used to illustrate basic patterns).

\subsection{Fipa structure}

Like the vast majority of the Bantu languages, Fipa has S V O word order, specifically S V IO DO, meaning that an indirect object must precede a direct object. This holds for all varieties described. However, as shown in this section, the different varieties differ in terms of which word orders are judged to be grammatical in double object constructions and in sentences that contain an object and a post-verbal adjunct, such as a temporal modifier.

\subsubsection{Word order in Fipa Double Object Constructions}

In Milanzi, the order of postverbal objects and adjuncts is invariable. Only S V IO DO is judged as acceptable (as in (1-a)), ${ }^{1}$ unless the indirect object is

1 Abbreviations used in glosses: $\mathrm{AUG}=$ augment; $\mathrm{APPL}=$ applicative; $\mathrm{DEM}=$ demonstrative; $\mathrm{FV}=$ final vowel; IMP = imperative; $\mathrm{INF}=$ infinitive LOC = locative; $\mathrm{NC}=$ noun class; $\mathrm{NEG}$ $=$ negation; $\mathrm{OM}=$ object marker (numbers refer to noun classes); $\mathrm{SM} / \mathrm{OM} 1 / 2 \mathrm{~S} / \mathrm{P}=$ (person) singular/plural (numbers refer to person not class); PERF = perfect; POSS = possessive; PRES 


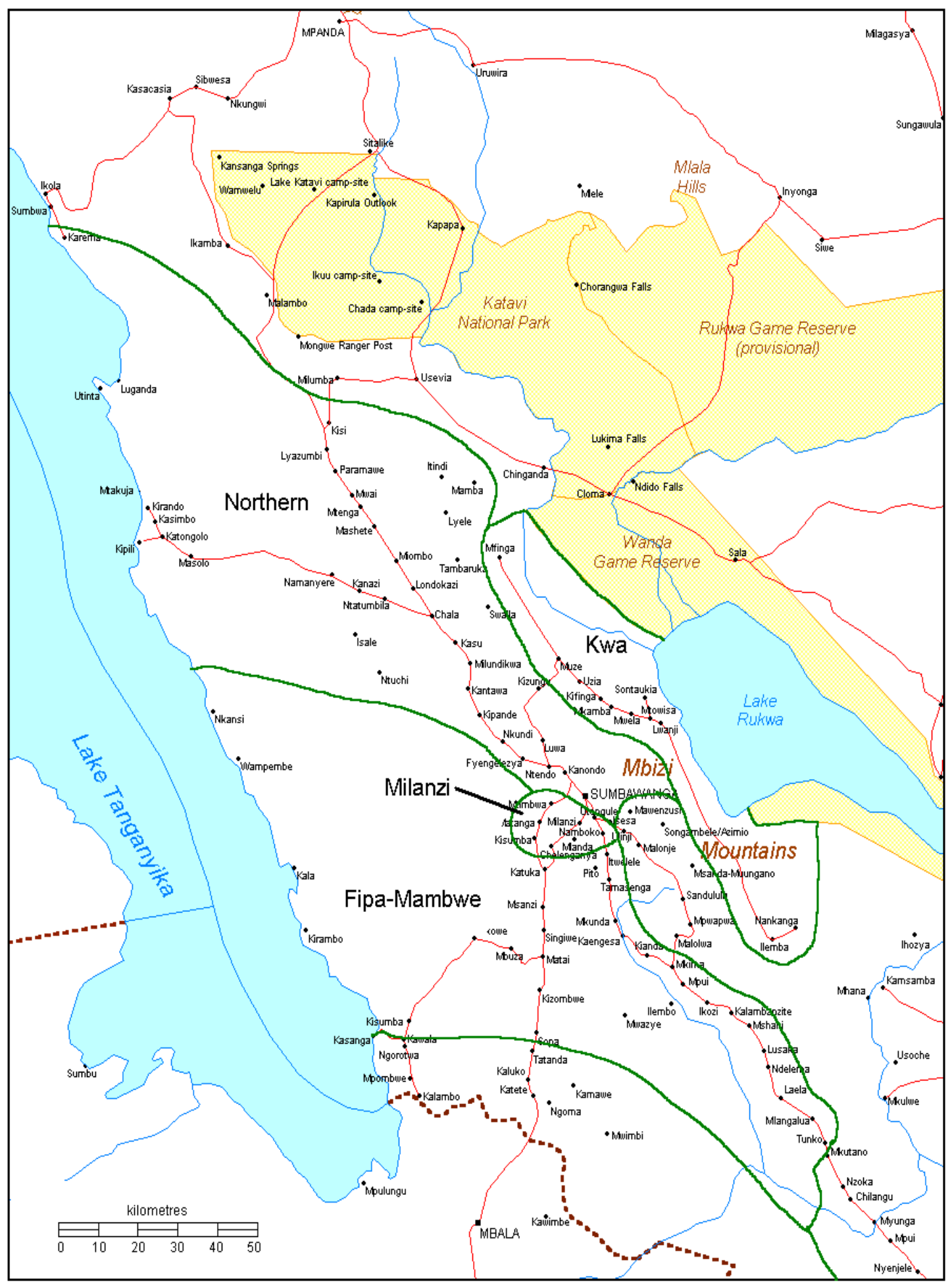

Figure 1: Fipa dialects (CSIL Tanzania 2009) 
right dislocated (which requires object-marking as well as a pause ${ }^{2}$ preceding the right dislocated element).
a. N-aa-pile $\quad \mho$-mw-aana I-chI-taabu. SM1 S-PST-give.PST AUG-1-child AUG-7-book
'I gave the child a book.' 3
b. *N-aa-pile I-chi-taabu $v$-mw-aana. SM1S-PST-give.PST AUG-7-book AUG-1-child
Int: 'I gave the child a book.'
c. N-aa-m-pile I-chi-taabu, $\mho$-mw-aana. SM1 S-PST-OM1-give.PST AUG-7-book AUG-1-child
'I gave her/him a book, the child.'

[Milanzi]

A temporal modifier cannot intervene between a verb and its object either.
a. N-aa-wiine $\quad$-mw-aana iyuulu.
SM1S-PST-see.PST AUG-1-child yesterday
'I saw the child yesterday.'
b. *N-aa-wiine iyuulu $v-m w-a a n a$.
SM1 S-PST-see.PST yesterday AUG-1-child
Int: 'I saw the child yesterday.'

[Milanzi]

Kwa has a much more flexible word order in double object constructions, where not only the word order of the direct and indirect object can be reversed but a temporal modifier can optionally precede an non-object marked object as well. This is illustrated in (3).
a. N-aa-pile
a-ya-ana i-piipii
iyuulu.
SM1 S-PST-give.PST AUG-2-child AUG-10.sweet yesterday
'I gave the children sweets yesterday.'
b. N-aa-pile i-piipii a-ya-ana iyuulu.
SM1 S-PST-give.PST AUG-10.sweet AUG-2-child yesterday
'I gave the children sweets yesterday.'
c. N-aa-pile i-piipii iyuulu a-ya-ana.
SM1 S-PST-give.PST AUG-10.sweet yesterday AUG-2-child
'I gave the children sweets yesterday.'

Nkansi, like Milanzi, does not allow any modifications of the basic word order. Nkansi speakers even rejected sentences with object-marked indirect objects

\footnotetext{
$=$ present tense $; \mathrm{PROG}=$ progressive $; \mathrm{PST}=$ past $; \mathrm{S}=($ person $)$ singular; $\mathrm{SM}=$ subject marker

2 Indicated by the comma in (1-c).

3 All Fipa varieties are fully tonal. Milanzi, Nkansi and Kwa have 7 vowels: [a] [e] [i] [I] [o] $[\mathrm{u}][\mathrm{v}]$ (Lungu and Mambwe only have [a] [e] [i] [o] [u]). Vowel length is contrastive, but there is also syntactically conditioned penultimate lengthening. The tonal analysis of Fipa is incomplete, because of this we do not mark tone in the sections dealing with morphosyntax.
} 
that deviated from the basic word order, as in (4-b) where the indirect object $\mho$-mw-aanafunzi 'student' follows the direct object.
a. N-aa-m-pile
$\mho$-mw-aanafunzi I-chI-taabu.
SM1 S-PST-OM1-give.PST AUG-1-student
AUG-7-book
'I gave a/the student a/the book.'
b. *N-aa-m-pile I-chI-taabu $\mho$-mw-aanafunzi. SM1 1-PST-OM1-give.PST AUG-7-book AUG-1-student
Int: 'I gave a/the student a/the book.'

[Nkansi]

Nkansi speakers also judged any temporal modifiers intervening between a verb and its object(s) as ungrammatical. Again, this even applied when the object was object marked, as in (5-b).
a. N-aa-m-wine $\quad \mho$-mw-aanafunzi iyuulu.
SM1 S-PST-OM1-see.PST AUG-1-student yesterday
'I saw a/the student yesterday.'
b. *N-aa-m-wine iyuulu $v$-mw-aanafunzi.
SM1 S-PST-OM1-see.PST yesterday AUG-1-student
Int: 'I saw a/the student yesterday.'
c. N-aa-wine Ing'oombe iyuulu.
SM1 S-PST-see.PST AUG-9.cow yesterday
'I saw a/the cow yesterday.'
d. *N-aa-wine iyuulu Ing'oombe.
SM1 S-PST-see.PST yesterday AUG-9.cow
Int: 'I saw a/the cow yesterday.'

[Nkansi]

Amongst the three core varieties of Fipa, Milanzi and Nkansi have similar word order properties, and these are the properties typically associated with strict word order Bantu languages, whereas Kwa differs drastically from these varieties, as well as the large number of Bantu languages which do not allow any temporals to intervene between a verb and its complements.

\subsubsection{Object marking}

In Fipa, only one object can be object-marked in a verb. Having two object markers in a verb, as in (6-b), is ungrammatical. In a double object construction, the object that is object marked must be the indirect object, as in (6-a), not the direct object, as in (6-c). 


\section{Int: 'I gave it to her/him.' \\ c. *N-aa-chi-p-ile u-wm-aana (I-chI-taabu). SM1 S-PST-OM7-give-PST AUG-1-child AUG-7-book Int: 'I gave it to the child.'}

[Mambwe]

In Fipa, object marking is very common for object nouns referring to humans. This pattern is illustrated in (7). There is a strong preference to mark first and second person pronouns, as in (7-c) and (7-d), proper names (as in (7-e)), kinship terms, and similar types of nouns. Sentences without object marking are judged as degraded or ungrammatical if the object belongs to this semantic group.
a. W-aa-(m)-um-ile $\quad$-mw-aana. SM1-PST-OM1-hit-PST AUG-1-child 'S/he ${ }^{4}$ hit the child.'
[Kwa]
b. W-aa-(y)-um-ile a-y-aana. SM1-PST-OM2-hit-PST AUG-2-child 'S/he hit the children.'
c. W-aa-*(n)-zan-ile inene. SM1-PST-OM1 1s-meet-PST me 'S/he met me.'
d. N-aa-*(ku)-lozile uwewe. SM1 S-PST-OM2S-see.PST you 'I saw you.'
e. N-aa-??(mu)-eni Julius. SM1 S-PST-OM1-see.PST 1Julius 'I saw Julius.'
f. $\mathrm{N}$-aa-? ${ }^{?}(\mathrm{~m})$-wine mama wane. SM1 S-PST-OM1-see.PST 1a.mother 1my 'I saw my mother.'

For non-humans objects that are not dislocated, as in (8-a) and (8-b), object marking is possible. In fact, in (8-c) it was preferred even for a non-human object like $\mathrm{t} / \mathrm{i}$-ng'ombe 'cow(s)'. As can be seen in (8-c), object marking does not change the basic S V IO DO word order in double object constructions.
a. N-aa-(mb)-wine teembo iyuulu. SM2S-PST-OM1-see.PST 1a.elephant yesterday 'I saw the elephant yesterday.'
b. A-ta-(fi)-lofya i-fi-suumbi. SM1-PERF-OM8-lose AUG-8-chair 'He lost the chairs.'

\footnotetext{
4 The class 1 subject marker appears as [a-] before a consonant, but as [u-] - which undergoes glide formation - before a vowel.
} 

c. N-aa-shi-p-ile i-ng'ombe I-chuulya iyuulu. SM1 S-PST-OM10-give-PST AUG-10cow AUG-7food yesterday 'I gave the cows food yesterday.'

[Milanzi]

In relative clauses, object marking the relativized object is grammatical. However, unlike in many other Bantu languages (cf. Henderson 2006; Marten et al. 2007; Riedel 2009), object marking is optional rather than obligatory for both human and non-human objects in Fipa relative clauses.
a. Aa-sungu ya-na Male w-aa-(ya)-lozile ya-ile u-koola. AUG.2-girl 2-REL 1Mary SM1-PST-OM2-see.PST SM2-go.PST INF.swim 'The girls who Mary saw are going swimming.'
b. I-vi-ntu vi-na n-aa-(vi)-tozile vy-aa-nwaama sana. AUG-8-thing 8.REL SM1S-PST-OM8-hold.PST SM8-PST-be.heavy very 'The things which I am holding are very heavy.'

\section{Wh-questions}

Wh-questions show the same subject- and object marking patterns as declarative sentences. Fipa does not have any special $w h$-morphology. The syntactic and intonational properties associated with questions do not differ across the three varieties discussed here.

\subsection{Subject questions}

In Fipa, a questioned subject appears in the preverbal position - analysable as specTP or equivalent projection - and agrees with the verb, just like a subject in a declarative clause. No relative morphology, demonstrative (as in the relative clauses in (9)) or copula (which might be indicative of a cleft structure) appears. Subject questions are shown in (10).
a. Wini a-kv-lw-ikala kuo? 1who SM1-TAM-PROG-live DEM17
'Who lives there?'
b. Chaani ch-onon-ile i-daraja?
7what SM7-damage-PST AUG-5bridge
'What damaged the bridge?' (Q6)
c. Wini na wini yi-isile?
1who and 1who SM2-come.PST
'Who all came?' (Q149)
d. Jirani chi w-aa-wine Juma?
5neighbour which sm1-PST-see.PsT 1Juma
'Which neighbour saw Juma?' (Q62)

[Milanzi] 
As the sentences in (10) show, this agreement pattern holds for all types of whelements that might question a subject, including +/- human agents, whichquestions and coordinated question words.

\subsection{Object questions}

\subsubsection{Word order and IAV (Immediately After the Verb) effects}

A questioned object follows the verb. There are potentially different positions relative to other postverbal elements where a wh-object will appear: either in IAV position or in the position where it would appear as a non-questioned element if it is a direct object.

If a direct object is questioned in a double object construction both orders of the two objects are possible.
a. A-lv-(ya)-langilizya chaani a-y-aana?
SM1-PROG-OM2-show 7what AUG-2-child
'What is he teaching the children?' (Q29)
b. A-lv-(ya)-langilızya a-y-aana chaanı?
SM1-PROG-OM2-show AUG-2-child 7what
'What is he teaching the children?'

However, there is a gradient difference between the two sentences, with (11-b) being judged as "only being used by young people".

In Nkansi as well, a questioned direct object can precede an indirect object, in contrast to a non-questioned direct object, as in (4-b).

$$
\begin{aligned}
& \text { W-aa-p-ile chaani } \mho \text {-mw-aanafunzi? } \\
& \text { SM2S-PST-give-PST 7what AUG-1-student } \\
& \text { 'What did you give the student?' }
\end{aligned}
$$

[Nkansi]

There is a preference for the questioned element to appear in the IAV position, and in particular for the indirect object to be left dislocated, as in (13-b).

$$
\begin{aligned}
& \text { a. W-aa-p-ile chaanI } \mho \text {-mw-aanafunzi? } \\
& \text { SM1-PST-give-PST 7what AUG-NC1-student } \\
& \text { 'What did you give to the student?' } \\
& \text { b. } \mho \text {-mw-aanafunzi w-aa-m-p-ile chaani? } \\
& \text { AUG-NC1-student SM1-PST-OM1-give-PsT 7what } \\
& \text { 'What did you give to the student?' (preferred to (13-a)) [Nkansi] }
\end{aligned}
$$

The same word order pattern is found with which-questions. Both possible orders are produced for a direct object which-question by the same speaker, as shown in (14). 
a. W-aa-m-p-ile nyoko I-chI-taabu chi? SM2S-PST-OM1-give-PST 1your.mother AUG-7-book which 'Which book did you give your mother?'

b. A-ku-nangizya $\mho$-m $\mho$-chuumba chi $\quad$ k $\mho$-ya-zazi? SM1-TAM-show AUG-NC3-place which LOC-2-parent 'Which sights will she show (her) parents?'(Q73)

With applied objects that are based on "promoted" adjuncts, such as the applied object in a reason applicative, both possible orders are produced, just as with non-applied objects. Compare the data in (15-a) and (15-b). In (15-a), the questioned applied object follows the direct object rather than appearing in the IAV position. In contrast, in (15-b), the $w h$-word is not an argument but an adjunct as there is no corresponding applicative but the same relative word order is found. Lastly, in (15-c), there is an applicative and the applied object precedes the direct object. (15-a) and (15-c) were produced spontaneously by the same speaker.
a. Mu-lv-kalıla I-chaakulya $\mho k \mho-c h a a n$ ?
SM2P-PROG-buy.APPL AUG-7food LOC17-7what
'For what are you (pl.) buying the food?' (Q25)
[Kwa]
b. U-lv-kala I-chakuulya Ichaa chaanı?
SM2s-PROG-buy AUG-7food 7ASSOC 7what
'For what are you (sg.) buying the food?'
c. U-many-ile ya-lv-kalıla chaani I-chaakulya?
SM2s-know-PST SM1-PROG-buy.APPL 7what AUG-7food
'Do you know what they are buying the food for?' (Q177) [Kwa]
[Nkansi]

While there is a preference for the questioned element to appear in IAV position, speakers of all dialects also produced sentences where a questioned-object does not appear in IAV position.

\subsubsection{Object marking}

In Fipa, object marking is optional but grammatical for any type of wh-object. Some wh-words, including wInI 'who' and chaanI 'what', belong to a particular noun class and have a singular/plural distinction which is reflected in the verbal agreement. The data in (16) shows a direct human wh-object (in a simple transitive clause) and an indirect human wh-object (in a ditransitive clause), both without object marking.
a. W-aa-wine wini?
SM1 S-PST-see.PST 1 who
'Who did you see?'
b. W-aa-p-ile winI I-chI-taabu?
SM1S-PST-give-PST 1who AUG-7-book


'Who did you give the book?'

[Nkansi]

The data in (17) show sentences with singular and plural who-objects that are used with object marking.
a. Maria a-lv-n-kalıla
WInI I-chi-taabu?
1Mary SM1-PROG-OM1-buy.APPL 1who AUG-7-book
'Who(m) is Mary buying a/the book for?' (Q23)
b. U-lø-mw-elekela wini I-keki?
SM2S-PROG-OM1-cook.APPL 1who AUG-9cake
'Who are you making a cake for?' (Q24)
c. U-chi-li w-aa-ya-pa ya-mwi I-keki?
SM2S-PRES-be SM2S-PST-OM2-give 2-which AUG-9cake
'Whom (pl.) ${ }^{5}$ haven't you (sg.) given cake (yet)?'

[Nkansi]

Both patterns are produced spontaneously by speakers of all Fipa dialects.

Likewise, inanimate $w h$-objects can be object marked and must agree in noun class just like non-questioned objects.
a. U-tu-chi-kala chaanı?
SM2S-PERF-OM7-buy 7what
'What have you bought?'
b. U-tu-vi-kala vyaanı?
SM2S-PERF-OM8-buy 8what
'What (pl.) have you bought?'
c. *U-tu-vi-kala chaanr?
SM2s-PERF-OM8-buy 7what
Int: 'What (pl.) have you bought?'

[Mambwe]

While object marking is not commonly found with $w h$-objects that question an inanimate object, there are examples of this pattern from spontaneously produced speech, as shown in (19).

$$
\begin{aligned}
& \text { Kunsi ku-chi-vuna! Ta-chi-chita chaanI na-cho? } \\
& \text { kunsi.IMP INF-OM7-break SM1s.NEG.PRES-OM7-do 7what and-7 } \\
& \text { 'Don't break it! I shouldn't do what with it?' }{ }^{6} \text { (Q160) }
\end{aligned}
$$

\subsection{Adverbial questions}

Question words such as how or when may also appear in IAV position in all dialects of Fipa. However, this seems to be less common than with questioned ob-

\footnotetext{
5 Ya-mwi translates as 'which people' and is used in this context to elicit specific members of a known set.

6 The morphology of the verb kunsi is not clear to us at this point.
} 
jects. Again, questioning licenses an element in the IAV position which would not be acceptable in this position in a declarative sentence with an overt postverbal (indirect) object.

In a where-question with an object, both possible orders of the object and the $w h$-word are grammatical. This is illustrated with Kwa data in (20-a).

$$
\begin{aligned}
& \text { A-lv-(ya)-langilizya kwI a-yaana? } \\
& \text { SM1-PROG-OM2-show where AUG-2child } \\
& \text { 'Where is he teaching the children?' } \\
& \text { b. A-lv-(ya)-langilizya a-yaana kwi? } \\
& \text { SM1-PROG-OM2-show AUG-2child where } \\
& \text { 'Where is he teaching the children?' }
\end{aligned}
$$

In Nkansi, both possible orders for a question with an object and a questioned locative/temporal adjunct were produced spontaneously.
a. Malia w-aa-pata kwI I-chi-taabu chi?
1Mary SM1-PST-get where AUG-7-book DEM7
'Where did Mary get this book?' (Q39)
b. W-aa-komengine n' iMali $\mho$-waanda chi?
SM2S-PST-meet.with.PST and 1Mary AUG-3day which
'When did you meet Mary?' (Q47)

[Nkansi]

The same pattern is found in Milanzi, as illustrated with the how-questions in (22).

(22) a. Maria a-lv-eleka i-keki ya chocolate uli? 1Mary SM1-PROG-cook AUG-9cake 9ASSOC 9chocolate how 'How does Mary make her chocolate cake?'

b. A-lv-koma inkwi uli?

'How is he cutting the firewood?'

c. Ya-n-china ul' apa-ntiyo?

SM2-TAM-dance how LOC16-9wedding

'How will they dance at the wedding?'

[Milanzi]

Again, both orders produced spontaneously in the same context:

(23) a. A-ta-tengenesha uli i-gari?

SM1-PERF-repair how AUG-5car

'How has (Mary) fixed the car? (Q52)'

b. A-ta-tengenesha i-gari uli?

SM1-PERF-repair AUG-5car how

'How has (Mary) fixed the car? (Q52)'

[Milanzi] 
As shown in (24) and (25-a), why and how come appear in clause-initial position just like their declarative counterparts (cf. (25-b)).

$$
\begin{aligned}
& \text { Mbona u-ta-kashile a-ma-ziiya? } \\
& \text { how.come SM2s-NEG-buy.PST AUG-6-milk }
\end{aligned}
$$$$
\text { 'How come you didn't buy milk?' (Q60) }
$$

[Milanzi]
a. Q: Kuno chaanI u-chi-li w-aa-kala a-ma-shiiya? why SM2S-NEG.PERS-be SM2s-PST-buy AUG-6-milk
'Why haven't you bought milk yet?'
b. A: Kuno iy-aa-shila umwi-duka. because SM5-PST-finish LOC18-5shop 'Because they have run out at the shop.'

Question words that question adjuncts show the same relatively free word order as the adjuncts they question.

\subsection{Multiple $w h$-questions}

Fipa allows multiple $w h$-questions. These are grammatical with any combination of argument or adjunct questions. This is illustrated for a subject and an object in (26),

$$
\begin{aligned}
& \text { Wini a-lv-leeta chaani? } \\
& \text { 1who SM1-PROG-bring 7what } \\
& \text { 'Who is bringing what?' (Q154) }
\end{aligned}
$$

for two objects in (27-a),

$$
\begin{aligned}
& \text { a. U-lv-kalila wini chaani? } \\
& \text { SM2s-PROG-buy.APPL 1who 7what } \\
& \text { 'Who(m) are you buying what?' (Q157) } \\
& \text { b. ?U-lv-kalıla chaani winı? } \\
& \text { SM2s-PROG-buy.APPL 7what 1who } \\
& \text { Int: 'Who(m) are you buying what?' }
\end{aligned}
$$

for an object and an adjunct in (28-a),

$$
\begin{aligned}
& \text { a. W-aa-wine wini kwi? } \\
& \text { SM2s-PST-see.PST 1who where } \\
& \text { 'Who(m) did you see where?' (Q155) } \\
& \text { b. *W-aa-wine kwi wini? } \\
& \text { SM2s-PST-see.PST where 1who } \\
& \text { Int: 'Who did you see where?' }
\end{aligned}
$$

and for two adjuncts in (29-a). 
(29)
a. W-aa-ile kwi li?
SM2S-PST.go.PST where when
'Where did you go when?'
b. W-aa-ile li kwi? (Q156)
SM2S-PST.go.PST when where
'Where did you go when?'

[Milanzi]

The fact that multiple $w h$-questions are grammatical might be considered to lend support to the analysis that question-elements are truly in situ in Fipa.

\subsection{Question morphosyntax}

Fipa does not generally require $w h$-words to appear in the IAV position or any other special position. However, there is a preference for postverbal whelements to appear in the IAV position. This also licenses word orders that are otherwise ungrammatical (eg. V Adj Obj, or V DO IO in Nkansi (12)) in Nkansi and Milanzi. To a large extent, wh-elements including subjects, predominantly have the same word order and morphological marking as their non$w h$-counterparts. The fact that multiple $w h$-questions are grammatical seems to lend further support to that.

\section{Question prosody}

\subsection{The boundary tone}

The question, in Fipa, is generally expressed by a boundary $\mathrm{H}(\mathrm{L}) \%$ tone. The tone appears on the last syllable of the Intonational Phrase (see below), which is then lengthened - see (30) and Figure 2, or (31). In our data, the boundary tone mostly has a falling shape (HL\%), but it can also appear as a high (H\%).

(30) mw-í́le kwî̀

SM2s-come where

'Where did you come from?'

$$
\begin{aligned}
& \text { m(v)-lư-k }{ }^{\uparrow} a l i ́ l(a) \quad \text { I-t f-á(a)-ku-'lyá } \quad \text {-kớ } \quad \text { (I)-tf-aanî: } \\
& \text { SM2S-TAM-buy(APPL) AUG-7-ASSOC-15-eat AUG-LOC17 AUG-7-what } \\
& \text { 'For what are you buying the food?' }
\end{aligned}
$$

The boundary tone also appears on the last syllable when the $w h$-word is sentenceinitial - cf. (32) and Figure 3.

$$
\begin{aligned}
& \text { WIní w-a-y-kála I-t } \int \text {-úulyâ' } \\
& \text { who sM1-TAM-OM1-buy AUG-7-food } \\
& \text { 'Who bought him (the) food?' }
\end{aligned}
$$




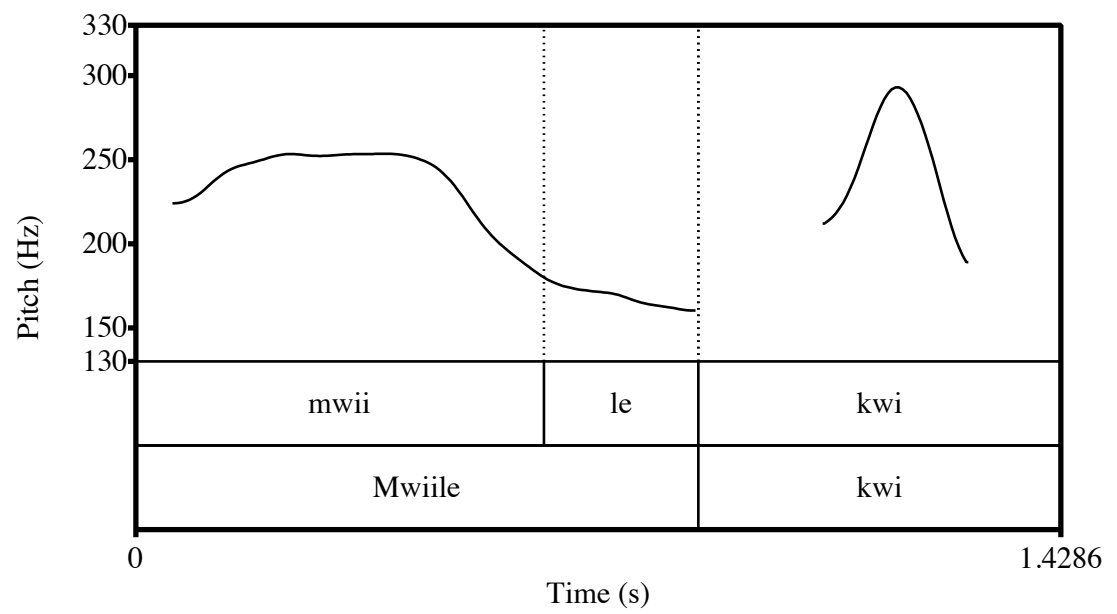

Figure 2: mwíle kwî: 'where did you come from?' - cf. (30)

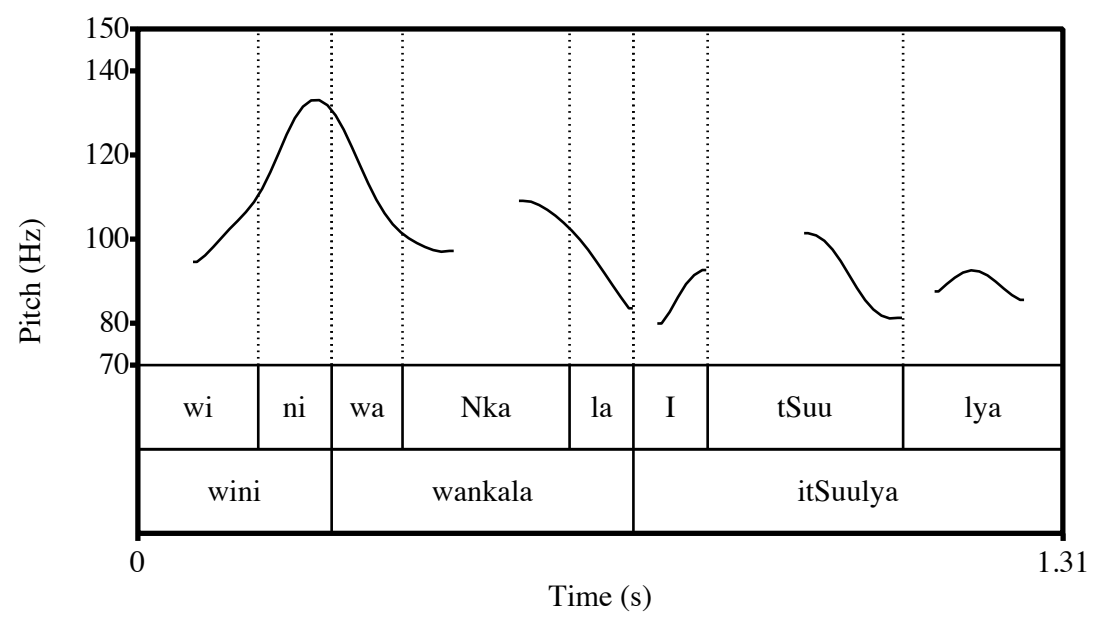

Figure 3: winí wankála itfúulyầ 'who bought him food?’ - cf. (32) 


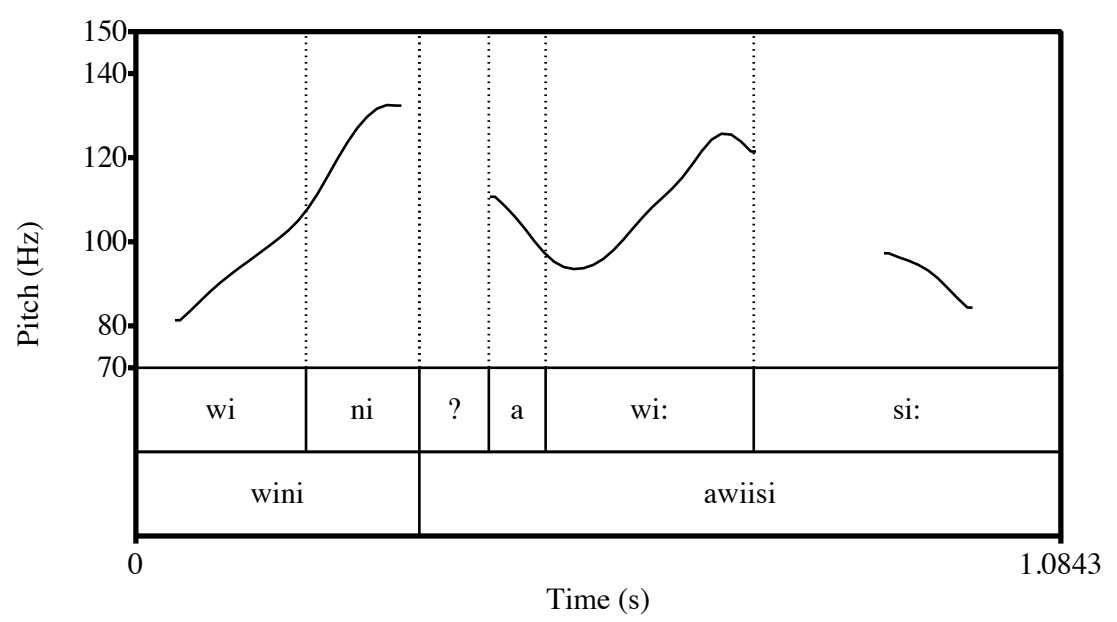

Figure 4: winí awíssì: 'who fell asleep?' - cf. (33)

When there is a lexical high on the penult, the boundary $\mathrm{H}(\mathrm{L}) \%$ is maintained, but is downstepped - see (33) and Figure 4.

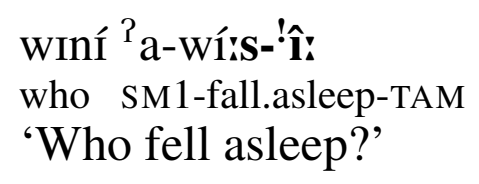

The boundary $\mathrm{H}(\mathrm{L}) \%$ is associated with the last vowel an Intonational Phrase. In (34), the boundary tone appears on the last word of the utterance. In (35), where the indirect object 'the children' is dislocated, the boundary tone appears on both the last and the penultimate words of the utterance - see also Figure 5. ${ }^{7}$

$$
\text { [ a-lv-láng(I)lízya a-yá-ana t t-aanî: ] }
$$
SM1-TAM-teach(CAUS) AUG-2-child 7-what

'What is he teaching the children?'8

$$
\begin{aligned}
& \text { [ a-lú-ya-lang(I)lízya kwî: } \left.]_{\text {IP }} \text { [ a-yá-anâ: }\right]_{I P} \\
& \text { SM1-TAM-OM2-teach(CAUS) where AUG-2-child } \\
& \text { 'Where is he teaching them, the children?' }
\end{aligned}
$$

\subsection{Other prosodic parameters}

While the boundary tone, along with the lengthening of the final syllable, seems to be the main prosodic parameter associated with questions, other prosodic features also occur frequently in questions. None of these are obligatory. They may thus be considered as 'enhancement features'.

7 NB: in (35), the second IP has an appendix realization: its register amplitude is reduced.

8 We do not know at this point of the research why the first tone appears on the third syllable, when it would have been expected on the second - cf. (35). 


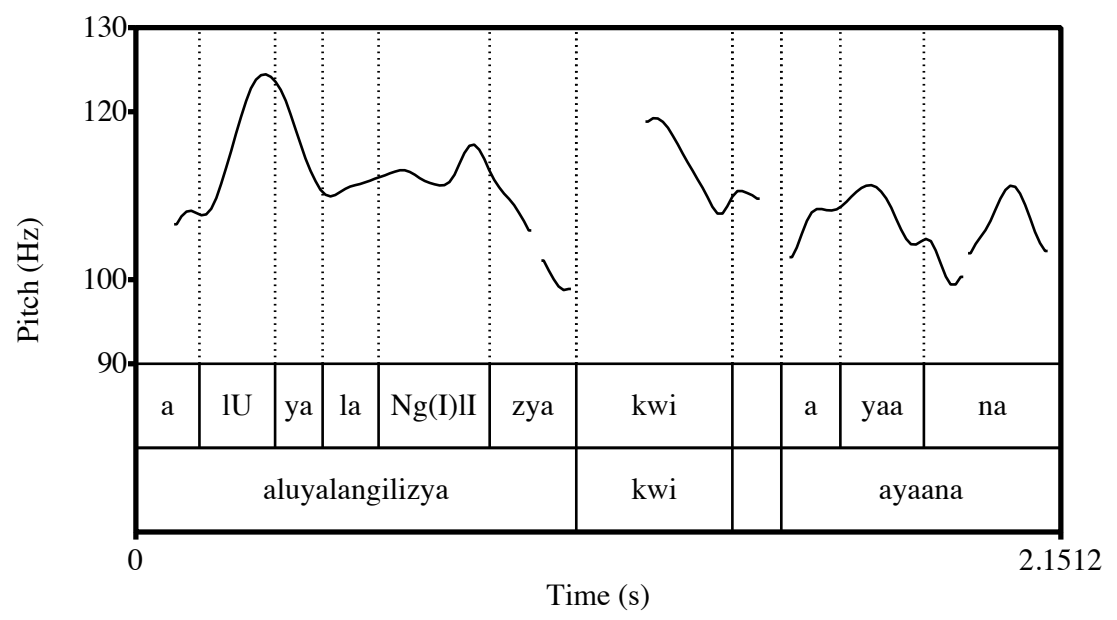

Figure 5: alơyalang(I)lízya kwî̀, ayáanâ: 'where is he teaching to them, the children?' - cf. (35)

First, the overall register of the question tends to be higher than the one of the answer or a declarative clause. Figure (6) shows that the register of the question (solid line) is higher than the register of the corresponding answer (dashed line) - the F0 range is $70-200 \mathrm{~Hz} .{ }^{9}$
a. tw-aa-vwáng-ile na winí: ?
SM2P-TAM-talk-TAM with 1who
'Who did we speak to?' SM2P-TAM-talk-TAM with mother=POSS 'We spoke with my mother.'
b. tw-aa-vwáng-ile na mam!á=ane

Figure 6 further shows that there is no downdrift in the question, while it does occur in the answer. This parameter seems to be consistent in the data.

Finally, another aspect that distinguishes the question from the declarative is the fact that there is, most of the time, no final devoicing in the former case, while devoicing is frequent in the latter case.

\subsection{Focus}

The prosodic shape of a $w h$-word may vary depending on its informational status. The word $t$-aaní 'what (7)?' for instance, receives a high tone on its last syllable when it occurs phrase finally - see (34) - or phrase initially - see (37) and Figure 7 - but it receives a high tone on its penult when it is the only new

9 One may consider that there is a high tone in the end of the question that is absent in the answer counterpart. However, it seems rather be the case that the syllables that precede the boundary $\mathrm{H}(\mathrm{L}) \%$ in the same prosodic word are lowered - see 38-b, for instance. 


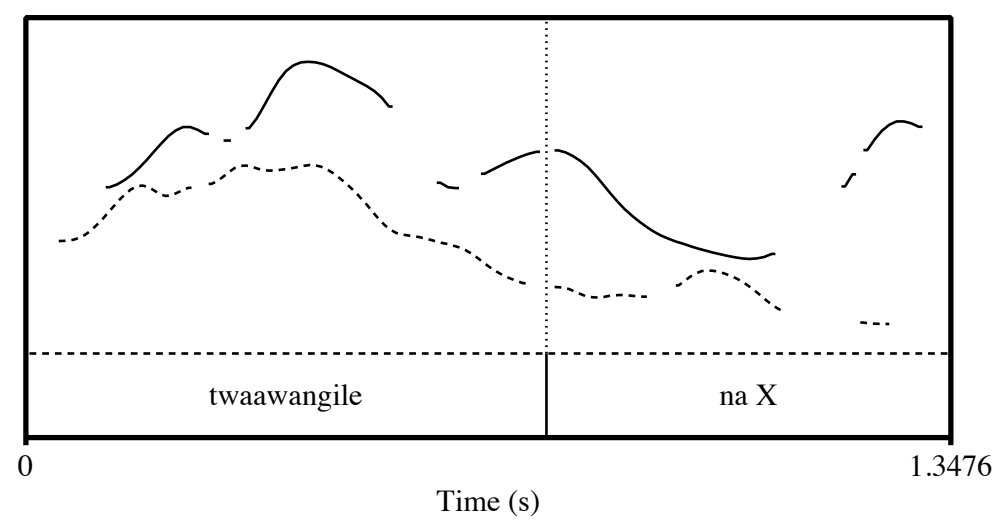

Figure 6: Comparison of the pitch tracks of the question (solid line) and answer (dashed line) in (36)

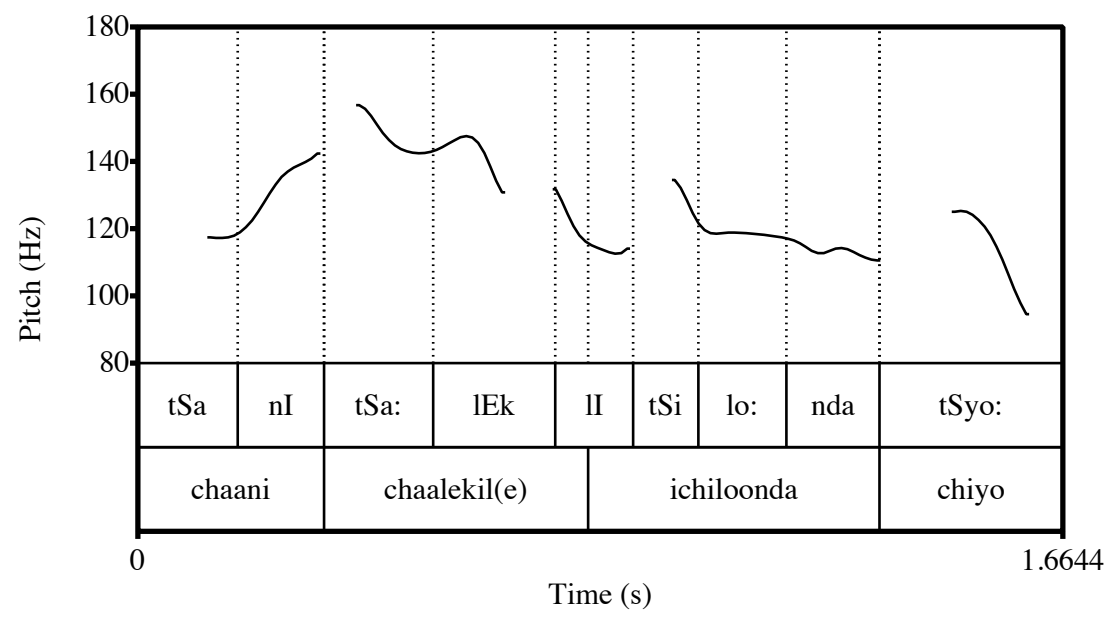

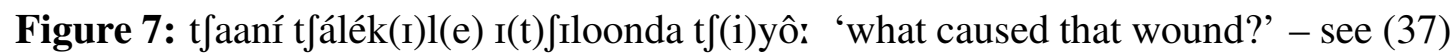

element in the sentence - (38-b) and Figure 8.

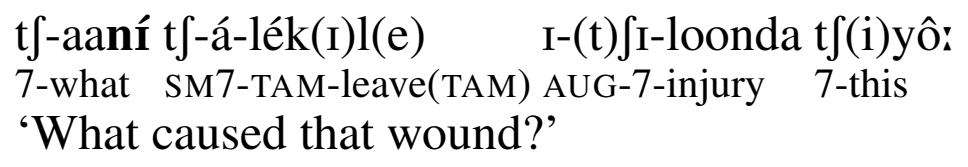
a. Do you know what happened?
b. aáwe, I-t f-áani 't f-áá-fúmilê:
no AUG-7-what SM7-TAM-appear(TAM)
'No, what happened?'

The same pattern seems to occur when the question is embeded - (39) and Figure 9. 


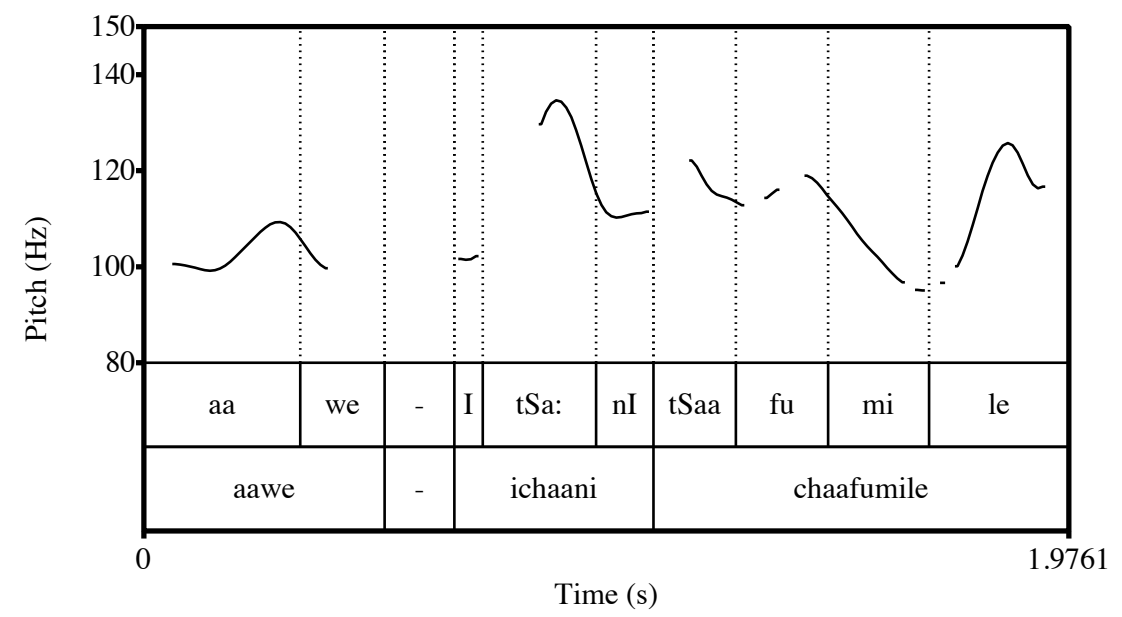

Figure 8: aáwe, it fáanı 'tfááfúmilê: ‘no! what happened?’ - see (38-b)

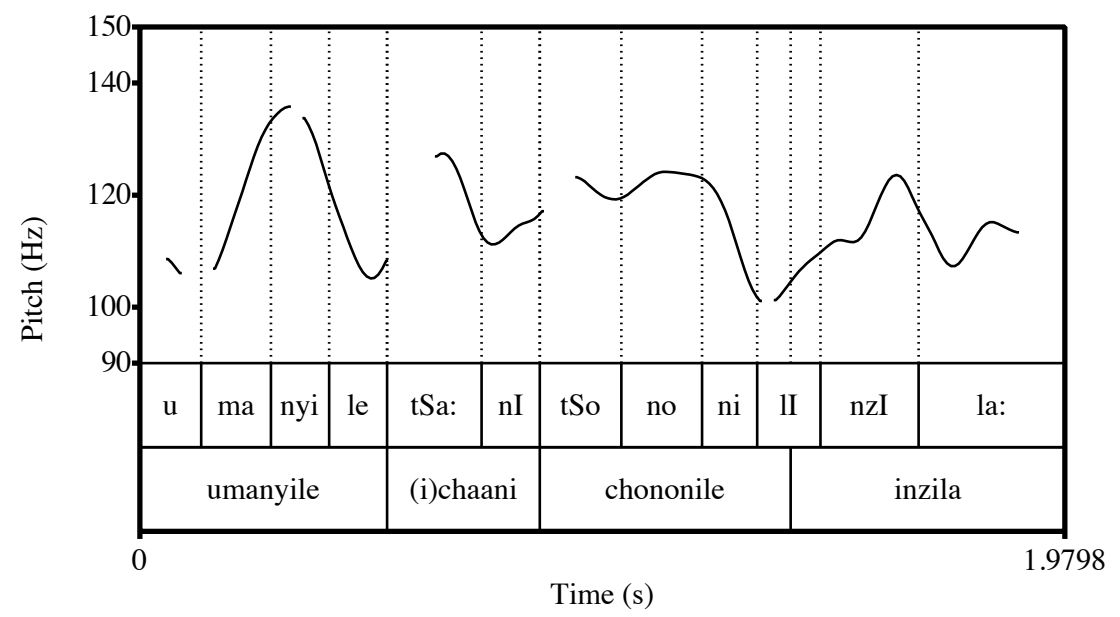

Figure 9: umányile (I-)tfáanı 'tfónónil(e) Inzí!lâ: 'Do you know what damaged the road?' - see (39) 


$$
\begin{array}{llc}
\text { u-mányile } & \text { (I-)t } \int \text {-áan } \quad \text { 't } \int \text {-ónónil(e) } & \text { I-n-Zí!lâ: } \\
\text { SM2s-know(TAM) (AUG-)7-what SM7[TAM]-damage(TAM) AUG-9-road } \\
\text { 'Do you know what damaged the road?' }
\end{array}
$$

\section{Conclusions}

While Fipa shows some IAV effects, wh-questions are generally only marked by the boundary tone $\mathrm{H}(\mathrm{L}) \%$ and optionally the other prosodic patterns that are associated with questions. Questions related to all types of arguments and adjuncts seems to share the syntactic properties of their non-questioned counterparts and multiple wh-questions are grammatical. We therefore tentatively conclude that Fipa $w h$-words are never dislocated. Further research on prosodic phrasing in Fipa may give support to this claim.

\section{References}

Bresnan, Joan \& Sam Mchombo (1987). Topic, Pronoun, and Agreement in Chichêwa. Language 63, 741-782.

Buell, Leston C. (2009). Evaluating the immediate postverbal position as a focus position in Zulu. In Selected Proceedings of the 38th Annual Conference on African Linguistics, 166172. Somerville, MA: Cascadilla Press.

Cheng, Lisa \& Laura J. Downing (2009). Where's the Topic in Zulu? Linguistic Review 26, 207-238.

Henderson, Brent (2006). The Syntax and Typology of Bantu Relative Clauses. Ph.D. thesis, University of Illinois at Urbana-Champaign.

Hyman, Larry M. \& Maria Polinsky (2006). Focus in Aghem. Forthcoming in Studies in Information Structure.

Hyman, Larry M. \& John Watters (1984). Auxiliary focus. Studies in African Linguistics 15, 233-273.

Lewis, M. Paul (ed.) (2009). Ethnologue: Languages of the World (Sixteenth edition). Dallas, Tex.: SIL International.

Marten, Lutz, Nancy C. Kula \& Nhlanhla Thwala (2007). Parameters of morpho-syntactic variation in Bantu. Transactions of the Philological Society 105, 253-338.

Mradi wa lugha za Tanzania (2009). Atlasi ya lugha za Tanzania. Dar es Salaam: Chuo Kikuu cha Dar es Salaam.

Ndayiragije, Juvénal (1999). Checking Economy. Linguistic Inquiry 30, 399-444.

Riedel, Kristina (2009). The Syntax of Object Marking in Sambaa: A Comparative Bantu Perspective. Ph.D. thesis, Universiteit Leiden.

Sabel, Joachim \& Jochen Zeller (2006). Wh-question formation in Nguni. In John Mugane, J. Hutchinson \& D. Worman (eds.), Selected Proceedings of the 35th Annual Conference on African Linguistics, 271-283. Somerville, MA: Cascadilla Press. 
van der Wal, Jenneke (2006). The disjoint verb form and an empty Immediate After Verb position in Makhuwa. ZAS Papers in Linguistics 43, 233-256.

Watters, John (1979). Focus in Aghem. In L. M. Hyman (ed.), Aghem grammatical structure. Los Angeles: Department of Linguistics, University of Southern California.

Woodward, Mark, Anna-Lena Lindfors \& Louise Nagler (2010). A sociolinguistic survey of the Fipa language community: Ethnic diversity and dialect diversity. Number 2010-023 in SIL Electronic Survey Reports. Dallas, TX: SIL International. 